\title{
PARAMETRIC STUDY ON THE PERFORMANCE OF A SOLID PARTICLE SOLAR RECEIVER
}

\author{
Taide Tan, Yitung Chen * and Zhuoqi Chen \\ Department of Mechanical Engineering \\ University of Nevada, Las Vegas, NV 89154
}

\author{
Submit to: Solar Energy \\ * Corresponding author \\ Dr.Yitung Chen \\ Department of Mechanical Engineering \\ University of Nevada Las Vegas \\ 4505 Maryland Parkway, Box 454027 \\ Las Vegas, NV 89154-4027 \\ Tel:(702) 895-1202 \\ Fax:(702) 895-4922 \\ E-mail: uuchen@nscee.edu
}




\section{Abstract}

Solid particle solar receivers (SPR) can be used as a high efficient solar energy absorber to collect concentrated radiation energy. The high temperature heat energy from SPRs can be applied as a heat source in a thermo-chemical water-splitting (TCWS) hydrogen production process. A parametric study has been conducted on a conceptual design from Sandia National Laboratories (SNL). A Computational Fluid Dynamics (CFD) model which includes the heat transfer and aerodynamics behaviors between the air and the particles is used to evaluate the performance of the SPR, both the cavity efficiency and the exit particle temperature. The main purpose of this study is to find the optimal design and working conditions of the SPR.

Key Words: Solid Particle Solar Receiver, Air-jet, Solar Energy, Hydrogen

\section{Introduction}

Hydrogen is a promising, clean energy carrier, and is potentially able to replace the use of fossil fuels which are facing the drawbacks of limited reserves and carbon dioxide emission around the world. Diverse chemical reaction cycles for hydrogen production are compared in scientific researches to obtain the environmentally friendly, large-scale, low cost and high efficiency process of hydrogen production (Abanades et al., 2006, Nielsen, 2005, Koroneos et al, 2004, Tan et al, 2009 and Tan et al, 2010). The solar-driven thermochemical water-splitting (TCWS) cycles may be an ideal choice for hydrogen production, which requires a high temperature input to split water into hydrogen and oxygen. For example, the sulfur-iodine (S-I) cycle of hydrogen production process requires a reaction temperature of $850{ }^{\circ} \mathrm{C}$ (Tan et al, 2009, Tan et al, 2010, Huang et al, 2005, and Huang et al, 2007). 
Solar central receiver systems are commonly used to concentrate the solar energy, which uses a heliostat field with large scale to reflect and focus the sunlight on a receiver located at the top of a solar tower. Inside of the solar receiver, small refractory particles fall down freely to create a curtain that directly absorbs the solar insolation, and act as a heat medium in the TCWS reaction after reaching a high temperature. Most solar receivers have an open aperture in the front to allow the concentrated sunlight to enter the cavity. However, a large amount of heat might be lost from the aperture by both convection and radiation (Tan et al, 2009 and Tan et al, 2010). Taussig investigated the influences of a protective air-jet on solid particle solar receivers (SPR) which reduces the convection heat loss by isolating the interiors of SPRs (Taussig, 1984). Another scheme to reduce the convective heat loss and particle loss is the face-down receivers with a horizontal aperture (Gintz 1987 and Vant-Hull 1999) and the receiver efficiency was analyzed by Roger (Roger et al, 2011).

Experiments on the design and material testing have been conducted by Sandia National Laboratories (SNL) since the 1980's. Evans et al. initiated the two-dimensional numerical modeling of an SPR with a computer code of PSI-Cell (particle source in cells) (Evans et al, 1985 and 1987). The aerodynamic and thermal interaction between gas flow and solid particles in a three-dimensional design was investigated by Chen et al., based on the conceptual design provided by SNL (Chen et al, 2007). Tan et al. conducted the investigation of wind effect on the performance of the SPRs and the protection of an aero-window formed by an air-jet (Tan et al, 2009 and Tan et al, 2010). The development of the SPR technology has been reviewed by Tan et al. (Tan et al, 2010). However, the parametric study has not been finished and the conclusions from the parametric study will 
provide a useful guide for the future design and development of the SPRs. The target of this paper is to find an optimal operating conditions and parameters for the SPR conceptual design.

\section{Physical Model, Mathematical Model and Numerical Model}

The SPR geometry and dimensions are shown in Figure1. The particles are pouring down from the top slot of the cavity to form a particle curtain which can absorb the solar irradiation directly. It is assumed that the particles are in a spherical shape (sphericity of 0.9). The solar energy is concentrated and directed to the receiver from the front aperture by heliostats on the ground. The irradiation is absorbed by the falling films directly, even considering the emitting, and scattering, etc. Assuming an adiabatic condition on the outer wall of the receiver, all the reflected, emitted heat will be absorbed by the inner wall and causes a temperature increase on the inner wall. This heat is not considered as a heat loss since the hot wall will transfer heat to the air and the particles on the other hand. The thermal interactions, including the particle-particle radiation, particle-wall radiation, particle-air convection, and air-wall convection, are taken into account in this analysis. The SPR consists of a cuboid cavity that is $2 \mathrm{~m}$ in width, $1.58 \mathrm{~m}$ in depth and $3 \mathrm{~m}$ in height. On the top of the cavity, a slot of $0.04 \mathrm{~m}$ by $1.5 \mathrm{~m}$ is designed for inserting the particles. An open aperture of $1.5 \mathrm{~m}$ by $1.5 \mathrm{~m}$ in front of the cavity allows the concentrated solar flux to enter the cavity. An air-jet with a dimension of $1.5 \mathrm{~m} \times 0.1 \mathrm{~m}$ is mounted at the top of the aperture and injects air downwards to form an aero-window and protect the cavity. To be pointed out, this conceptual design has a much smaller dimension than the general commercial SPRs and the following parametric study results may need to be adjusted according to the practical dimensions. 
The air entrainment was proven to be important in the experimental work of Evans and Koroneos (Evans et al, 1985 and 1987, and Koroneos, et al, 2004), in which the velocity of the particles was significantly higher than the terminal velocity corresponding to an isolated particle in a quiescent environment, due to the two way momentum and the thermal coupling. A buoyant force is generated because the air near the particle curtain is warmed up by the solar energy and by the hot particles. The buoyant force results in an increase of the particle residence time, which helps each particle to stay in the radiant flux field for a longer time. From the experimental work by Hruby, the particle-particle collision was infrequent if the particle volume fraction was very small, such as less than 1\% (Hruby et. al, 1984 and 1986). Therefore, the momentum transfer between the particles is not included in this study.

In this research, several assumptions in the numerical model are made to investigate the performance of SPR. For example, the solar flux is set at a fixed value. The particles are assumed to be of uniform size with a spherical shape. The wall of SPR is assumed to be adiabatic, etc. In this CFD model, a two-way coupled Euler-Lagrange method is implemented. The momentum and heat transfer between the particles and gas are considered. The governing equations used to express the gas-solid thermal aerodynamics are solved in the Cartesian coordinate system with a control-volume finite difference method which is introduced by Patankar (Patankar, 1980). A Finite Volume Method solver is used to simulate the performance of the solid particle solar receiver. From the previous study by Tan and Chen, the average velocity of air inside the cavity is around $1.2 \mathrm{~m} / \mathrm{s}$ for the baseline case (Tan et al, 2009 and 2010, Chen et al, 2007). For the typical size of the receiver, we take $2 \mathrm{~m}$ as the characteristic dimension. Therefore, the Reynolds 
number of the flow inside the cavity is estimated at about $1.6 \times 10^{5}$ for the typical operating conditions, which typically induces a turbulent flow. The governing equations for the air flow, for the air-particle interactions, and for the solar radiation have been presented and analyzed in the references (Tan et al, 2009 and 2010, Chen et al, 2007, Fluent Inc., 2005). A solar ray tracing algorithm is used to predict the solar incidence. It takes a beam which is modeled using the position of the sun vector and illumination parameters, applies it to any wall or inlet/outlet boundary conditions, and performs a face-by-face shading analysis to determine well-defined shadows on all boundaries (Koroneos et al, 2004). The detailed information related to the physical properties of the solid particles and gas flows in the numerical model is listed in Table 1.

The working efficiencies and exit particle temperatures are two important indexes to evaluate the thermal performance of an SPR. The cavity efficiency is defined as:

$$
\eta=\frac{Q_{P}}{Q_{\text {inc }}}
$$

where $Q_{P}$ is the energy absorbed by the solid particles, and $Q_{i n c}$ is the total incident solar energy that enters the cavity through the aperture. The total incident solar energy value is assumed to be constant. The radiation loss percentage is defined as the ratio of the radiation heat loss $Q_{\text {radloss }}$ through the open aperture by the total incident solar energy $Q_{i n c}$. Similarly, the convection heat loss percentage is defined as the ratio of the convection heat loss through the open aperture $Q_{\text {cnvloss }}$ by the total incident solar energy $Q_{\text {inc }}$.

\section{Results and Discussions}




\subsection{Calculating Domain Selection}

The domain independent study has been conducted in Ref. (Tan et al, 2009) considering the wind effect. As for this parametric study, the wind effect is not considered. Therefore, a smaller calculating domain is sufficient for the simulation. In order to reduce the calculating time, the approaching length (the distance between the front edge of the calculating domain to the front aperture) is set at $3 \mathrm{~m}$ (added a domain from $\mathrm{Z}=1.58 \mathrm{~m}$ to $\mathrm{Z}=4.58 \mathrm{~m}$ in additional to the cavity). The side space (the distance between the side edge of calculating domain to the side wall of the receiver) is set at $1 \mathrm{~m}$ (added a domain from $X=-1 \mathrm{~m}$ to $X=0$, and from $X=2 \mathrm{~m}$ to $X=3 \mathrm{~m}$, from $Y=-1$ to $Y=0$ and from $Y=3 \mathrm{~m}$ to $Y=4$ $\mathrm{m})$.

\subsection{Mesh Independent Study}

Several computational mesh systems have been generated to check the grid independence. Mesh systems with 197,892, 332,960, 533,400, 717,094, and 909,441 cells have been investigated. The typical examination location of Line 1, Line 2, Point A and Point B are shown in Figure 1. Line 1 is the straight line between the Point $(1 \mathrm{~m}, 1.4 \mathrm{~m}, 0$ m) and Point $(1 \mathrm{~m}, 1.4 \mathrm{~m}, 1.58 \mathrm{~m})$. Line 2 is the straight line between the Point $(0 \mathrm{~m}, 0.7$ $\mathrm{m}, 0.8 \mathrm{~m})$ and Point $(2 \mathrm{~m}, 0.7 \mathrm{~m}, 0.8 \mathrm{~m})$. Point A locates at $(1 \mathrm{~m}, 1.4 \mathrm{~m}, 0.3 \mathrm{~m})$ and Point B is at $(0.15 \mathrm{~m}, 0.7 \mathrm{~m}, 0.8 \mathrm{~m})$, as can be seen from Figure 1 .

Figure 2 shows the velocity distributions along Line 1 and Figure 3 shows the velocity distributions along Line 2 . From the comparison, the velocity magnitudes agree very well with each other except for the mesh with 197,892 cells. Figures 4 and 5 show the relative error percentages of the velocity magnitudes at Point A and Point B. From the comparison, the mesh system with 533,400 cells has relative error percentages of velocity 
under $10 \%$ for at both points, compared with the finest mesh. To save the computational resources and time, a computational mesh system with 533,400 cells is selected in the study. The mesh is refined near the walls, near the open aperture and near the particle curtain region of the SPR, which can provide an accurate result for the regions with large pressure, temperature and velocity gradients.

From Figure 2, we can observe the change of velocity magnitude along Line 1. On the back wall, the velocity is zero due to the non-slip boundary condition. At the location of $Z=0.25 \mathrm{~m}$ from where the particles are inserted, the particles' momentum induces the maximum velocity of the air. In the space between the backside wall and the particle curtain, there is an air circulation. Therefore, a high velocity can be observed at the locations close to the wall and close to the curtain. Whereas, in the center region of this space, a low velocity is observed. Similarly, there is another air circulation between the front wall and the particle curtain. Therefore, an increase of the velocity can be observed at location of $Z=1.55 \mathrm{~m}$. It is easy to notice the velocity magnitude follows a symmetrical pattern along Line 2 in Figure 3. Similarly, the velocity is zero on both side walls and has an increase at the regions close to the call due to the air circulation induced by the particle and by the temperature gradient.

\subsection{The Influence of Air-jet Velocities on the Performance of the SPR}

From the previous study (Tan et al, 2009 and 2010), the hot air can escape from the cavity and the cold air can invade into the cavity from the open aperture if there is no protection. An air-jet is introduced to enhance the performance of the SPR by forming an aero-window at the aperture. The air-jet injects a transparent gas stream across the 
aperture to isolate the interior from the ambient environment. The additional benefit of the aero-window is to prevent the particles escaping from the cavity.

The air-jet velocities of 0 (no air-jet flow), 2, 4, 6, 8, and $10 \mathrm{~m} / \mathrm{s}$ have been investigated to find the optimal velocity magnitude of the air-jet for the SPR. All other operating conditions keep the same during the parametric study. The mass flow of the solid particles is $5 \mathrm{~kg} / \mathrm{s}$ with an initial insert downward speed $0.088 \mathrm{~m} / \mathrm{s}$. The air-jet flow temperature is at $300 \mathrm{~K}$, and 920 suns are used for the solar flux value. The diameter of the solid particles is 650 microns, with an initial temperature of $873 \mathrm{~K}$.

Figure 6 illustrates the air flow pattern at the plane $x=1 \mathrm{~m}$ (center plane of the SPR) without an air-jet flow $\left(V_{a j}=0\right)$. The temperature contours at the center plane is shown in Figure 7. It can be seen that a buoyancy force is generated near the particle curtain as a result of the solar radiation. There is a strong air circulation in the region between the aperture and bottom of the particle curtain, as shown in Figure 6. A large amount of air from the environment enters the cavity through the bottom of the aperture. Since the environmental air has a much lower temperature than the cavity air, the cavity efficiency and exit particle temperature are reduced greatly due to the energy loss by convection. The temperature contours in Figure 7 show that the temperature decreases near the air circulation inside the cavity. From the temperature contours, it can be seen that the maximum temperature can reach $2100 \mathrm{~K}$. However, this high temperature only takes place on the backside wall of the cavity, on which the main solar energy can reach through the open aperture. Due to the large radiation and convection heat transfer, this maximum temperature region is very small and is on the wall only. 
By introducing the air-jet flow, the heat lost from the escaped hot air and the invaded cold air has been reduced. For the cases of air-jet velocity magnitudes less than $8 \mathrm{~m} / \mathrm{s}$, the air-jet flow is not powerful enough to form an aero-window and to cover the whole aperture. As the air-jet velocity increases, much more hot air is kept inside the cavity and leads to an increase of the cavity efficiency and the exit particle temperature. Figure 8 shows the air flow pattern and Figure 9 shows the temperature contours at the center plane $(\mathrm{x}=1 \mathrm{~m})$ for the case with air-jet flow of $V_{a j}=8 \mathrm{~m} / \mathrm{s}$. From the plots, the aerowindow is formed and the air-jet flow covers the whole aperture of the SPR. Inside the cavity, there is a counter clockwise air circulation, which could lift the particles inside the cavity for a longer time to absorb more solar energy. From the temperature contour in Figure 9, the hot air is enclosed by the air-jet, and the back wall temperature is much higher than the case without the protection of an air-jet.

Figure 10 shows the cavity efficiencies and the average particle exit temperatures as a function of the air-jet velocities. The air-jet velocity of $8 \mathrm{~m} / \mathrm{s}$ provides the highest efficiency, even better than $10 \mathrm{~m} / \mathrm{s}$. The reason is that a small part of the cold air from the air-jet flow may enter the cavity and causes a larger convection loss when the air-jet velocity reaches $10 \mathrm{~m} / \mathrm{s}$ or higher. For the average exit particle temperature, the SPR with $8 \mathrm{~m} / \mathrm{s}$ gives a maximum output temperature of $1155 \mathrm{~K}$ that satisfies the thermo-chemical reaction temperature $850{ }^{\circ} \mathrm{C}$ for the S-I cycle.

Figure 11 shows the radiation loss and convection loss percentages as a function of the air-jet velocity. The radiation loss percentage value is almost constant in the tested air-jet velocity range of $0 \mathrm{~m} / \mathrm{s}-10 \mathrm{~m} / \mathrm{s}$, which occupies about $30 \%$ of the total incident solar energy. The convection loss percentage keeps decreasing until the air-jet velocity 
reaches $8 \mathrm{~m} / \mathrm{s}$, which gives the best performance of the SPR in the tested velocity range. These results prove that an air-jet with a proper injection velocity is capable of reducing the convection heat loss and enhance the performance of an SPR.

For the baseline case in which there is no air-jet flow, the integrated energy source is $2070 \mathrm{~kW}$ and the particle size is $650 \mu \mathrm{m}$. The energy absorbed by particles is $803.16 \mathrm{~kW}$ which gives a cavity efficiency of $38.8 \%$. The heat loss by radiation is $631.35 \mathrm{~kW}$ (30.5\%), and the convection loss is $635.49 \mathrm{~kW}(30.7 \%)$. The details are summarized in the table 2 . From the analysis, it can be noticed that the low cavity efficiency is due to the large convective energy loss from the front open aperture, and the radiation loss from the front aperture.

\subsection{The Influence of Air-jet Temperatures on the Performance of the SPR}

Since $300 \mathrm{~K}$ is a low initial temperature for an air-jet, the cold air of the air-jet may enter the cavity and cause low efficiency of the SPR. The aero-window of the cold air also causes efficiency decrease by convection with the cavity air. It is necessary to check whether an increase of the air-jet initial temperature can lead to a better performance of the SPR. At the same time, it is possible to pre-heat the air-jet air by recuperate the heat from the particle container or heat exchanger. A typical temperature $700 \mathrm{~K}$ is examined. All other operating conditions keep the same during the calculation.

The air-jet velocity is set at $8 \mathrm{~m} / \mathrm{s}$, and the initial temperature is $700 \mathrm{~K}$ in this case. To characterize the air flow clearly, the air flow stream lines and flow vector patterns are shown in Figure 12. Even though the preheated air-jet flow heats a little of the air near the aperture, the pre-heated air jet flow does not cover the aperture as expected. The stream lines with high temperature are pushed forwards, and cause a leakage in the 
bottom of the aperture. Cold air from the surroundings is drawn into the cavity of the SPR. This is because the pre-heated air from the air-jet causes a buoyancy force and forms a strong backflow of air that pushes the air-jet flow away from the aperture. For the comparison, the air-jet stream lines and flow vector patterns of the case with $V_{a j}=8 \mathrm{~m} / \mathrm{s}$, and $T_{a j}=300 \mathrm{~K}$ are shown in Figure 13. The stream lines show that an aero-window is formed and seals the aperture very well. Table 3 summarizes the performance of the SPR with air-jet temperature in the range of $300 \mathrm{~K}$ to $700 \mathrm{~K}$, and a velocity range of $6 \mathrm{~m} / \mathrm{s}$ to $10 \mathrm{~m} / \mathrm{s}$. From Table 3, there is no big difference between these cases. Therefore, the increase of the air-jet initial temperature does not show much improvement in the performance of the SPR and this method is not recommended.

\subsection{The Particle Diameters}

The working media for the solid-particle curtain is a commercially available product from CARBO Ceramics called CARBO-HSP. It is mainly bauxite and includes $7 \%$ iron oxide, which makes the particles in black color and contributes to its desirable optical properties (Tan et al, 2009 and 2010, Chen et al, 2007). The detailed information of particle selection has been analyzed by Tan considering the thermal performance, agglomeration, and cost, etc (Tan et. al, 2010).

Chen stated that the solid particle with a smaller diameter is more capable of reaching a higher temperature from his simulation, without considering the air-jet protection (Chen et al, 2007). Hruby also concluded that a smaller particle size can bring both higher cavity efficiency and higher exit temperature (Hruby et. al, 1984 and 1986). 
The trajectory of the solid particle is predicted by integrating the force balance on the particle. The force balance on each particle equals the particle inertia force with the force acting on each particle. The buoyancy force acts more predominantly on particles with smaller diameter than larger ones, which helps smaller particles to stay in the cavity for a longer time, and absorb more solar irradiation. Based on the model of a two-way coupled Euler-Lagrange method, the calculation includes the exchange of heat and momentum between the gas phase and particles. But it neglects the effect of the nearby particles on the drag force. This assumption is reasonable when the particle volume fraction is very small, such as less than $1 \%$, and the particle distance is much larger than the diameter of the particles (Tan et al, 2009 and 2010, Chen et al, 2007). The typical values of the volume fractions are less than $0.42 \%$ in this study.

The performances of the SPR have been evaluated on the particles of different diameters, with the protection of an air-jet. Figure 14 illustrates the cavity efficiency of the SPR and the average exit particle temperature as a function of particle diameters with an air-jet velocity of $8 \mathrm{~m} / \mathrm{s}$. A smaller particle size leads to a higher average exit particle temperature, and results in higher cavity efficiency. However, the smaller particles may disperse all around due to strong turbulence air flow pattern inside the cavity, which will cause particle loss and energy loss. Most of the particles stay to form a relatively uniform curtain without any particle mass loss, until the diameter of particles decreases to 60 microns. Some particles are blown away from the open aperture of the receiver by the air flow in the cavity. The loss of the particles causes a dramatic decrease of the cavity efficiency, even though the remaining particles have a high exit temperature. Therefore, the solid particle with a diameter in the range of 70-80 microns gives the best 
performance of SPR theoretically. The particles of 70-80 microns in diameter can bring the cavity efficiency of $85 \%$ and average exit particle temperature of $1199 \mathrm{~K}$, with an airjet temperature of $300 \mathrm{~K}$, air-jet velocity of $8 \mathrm{~m} / \mathrm{s}$, solid particle mass flow rate of $5 \mathrm{~kg} / \mathrm{s}$, and under the solar radiation of 920 suns.

\subsection{Particle Insert Mass Flow Rates}

The control of mass flow rates can be realized by adjusting the opening size of the particle inlet. And the volume percentage of particle inside the cavity is still under $1 \%$ assumption when the mass flow rate is below $7 \mathrm{~kg} / \mathrm{s}$. The particle-particle collision can be still neglected when the mass flow rate is below $7 \mathrm{~kg} / \mathrm{s}$. The mass flow rates of $3,4,5,6$,

$7 \mathrm{~kg} / \mathrm{s}$ have been investigated and the results are shown in Figure 15. Figure 15 demonstrates that to increase the particle mass flow rate leads to an increase in the cavity efficiency and a decrease in the average exit particle temperature. The explanation is that larger mass flow rates can bring more particles to transport absorbed solar energy, which will increase the overall efficiency. On the other hand, the limited incident solar flux has been distributed to more particles and consequently decrease the average exit temperature of particles.

\section{Conclusions}

This paper presents the parametric study on the performance of the SPR with the presence of an air-jet. In this study, a three-dimensional numerical model for the SPR was generated. The investigation aims at providing useful information to guide the design of a high performance SPR, which can reach the required chemical reaction temperature for the TCWS cycles, such as S-I cycle. The main operating conditions and parameters of the 
SPR are studied to identify the optimal design, including: air-jet velocity, air-jet temperature, particle size, and particle mass flow rate, etc.

The receiver performance can be enhanced by applying an air-jet design. A velocity of $8 \mathrm{~m} / \mathrm{s}$ for the air-jet can form a good aero-window and provide a fairly good performance, over the testing range of $0 \mathrm{~m} / \mathrm{s}$ to $10 \mathrm{~m} / \mathrm{s}$. Through applying smaller particle size in the SPR, a higher exit particle temperature and efficiency can be obtained. However, a small particle size may cause a loss of the particles from the open aperture, such as 60 microns in diameter or smaller. From the parametric study, solid particles of 70-80 microns in diameter show the best performance of the SPR. The particles of 70-80 microns in diameter can bring the cavity efficiency of $85 \%$ and average exit particle temperature of $1199 \mathrm{~K}$, with an air-jet temperature of $300 \mathrm{~K}$, air-jet velocity of $8 \mathrm{~m} / \mathrm{s}$, solid particle mass flow rate of $5 \mathrm{~kg} / \mathrm{s}$, and under the solar radiation of 920 suns. The exit particle temperature from this conceptual design of SPR can satisfy the required chemical reaction temperature of the S-I TCWS cycle for producing hydrogen. To preheat the airjet flow did not show an improvement on the cavity efficiency and the exit particle temperature and it is not recommended. To increase the particle mass flow rate increases the cavity efficiency, and decreases the average exit temperature of particles.

\section{Acknowledgments}

This research is supported by the U.S. Department of Energy, Hydrogen Program (Grant No. DE-FG36-03GO13062).

\section{Nomenclature}

$Q_{P}=$ energy absorbed by the solid particles 


$$
\begin{aligned}
& Q_{i n c}=\text { total incident solar energy through the aperture } \\
& Q_{\text {radloss }}=\text { radiation heat loss } \\
& Q_{c n v l o s s}=\text { convection heat loss } \\
& \operatorname{Re}=\text { Reynolds number } \\
& T=\text { temperature }(\mathrm{K}) \\
& T_{P-e x i t}=\text { average exit particle temperature }(\mathrm{K}) \\
& T_{P}=\text { particle temperature }(\mathrm{K}) \\
& T_{a j}=\text { air-jet Temperatures }(\mathrm{K}) \\
& V_{a j}=\text { air-jet velocity } \\
& x, y, z=\text { coordinates } \\
& \eta=\text { cavity efficiency }
\end{aligned}
$$

\title{
References
}

\author{
Abanades S., Chsrvin P., Flamant G., and Neveu P., 2006, Screening of water-splitting \\ thermochemical cycles potentially attractive for hydrogen production by concentrated \\ solar energy, Energy, Vol. 31, pp. 2805-2822. \\ Nielsen T. R., 2005, Manufacture of hydrogen, Catalysis Today, Vol.106, pp.293-296. \\ Koroneos C., Dompros A., Roumbas G., Moussiopoulos N., 2004, Life cycle assessment \\ of hydrogen fuel production processes, Int. J. Hydrogen Energy, Vol. 29, pp. 1443-1450.
}


Tan T., Chen Y., Chen Z., Siegel N. and Kolb G. J., 2009, Wind Effect on the Performance of Solid Particle Solar Receivers with and without the Protection of an Aerowindow, Solar Energy, Volume 83, Issue 10, Pages 1815-1827.

Tan T. and Chen Y., 2010, Review of Study on Solid Particle Solar Receivers, Renewable and Sustainable Energy Reviews, 14, Pages 265-276.

Huang C., Raissi A. T., 2005, Analysis of Sulfur-Iodine Thermochemical Cycle for Solar Hydrogen Production. Part I: Decomposition of Sulfuric Acid, Solar Energy, vol. 78 (5), pp. 632-646.

Huang C., Raissi A. T., 2007, Analysis of sulfur-iodine therochemical cycle for solar hydrogen production. Part II: Steam reforming and autothermal steam reforming, Journal of Power Sources, Vol 163, Issue 2, Pages 637-644.

Taussig R. T., 1984, Aerowindow for Center Solar Receivers, ASME, 84-WA/Sol-14, pp. 1-12.

Gintz, J. R., 1987, Closed-Cycle, High-Temperature Central Receiver Concept for Solar Electric Power, Boeing Engineering and Construction, Seattle, Washington, Electric Power Research Institute, Palo Alto, CA, Final Report ER-629.

Vant-Hull, L. L., Izygon, M. E., and Imhof, A., 1999, Optimization of Central Receiver Fields to Interface With Applications Requiring High Flux Density Receivers, 9th International Symposium on Solar Thermal Concentrating Technologies 1998, [J. Phys. IV 9, Pr3-65-Pr3-70 (1999)].

Roger,M., Amsbeck, L., Gobereit, B., Buck, R., 2011, Face-Down Solid Particle Receiver Using Recirculation, Journal of Solar Energy Engineering. 
Evans G.., Houf W., Grief R.. and Crowe C., 1985, Gas Particle Flow Within a High Temperature Cavity Including the Effects of Thermal Radiation, Heat Transfer-Denver 1985, ASME, Vol.81, pp.245.

Evans G.., Houf W., Grief R., and Crowe C., 1987, Gas-Particle Flow Within a High Temperature Solar Cavity Receiver Including Radiation Heat Transfer, Journal of Solar Energy Engineering, Vol. 109, pp.134-142.

Evans G.., Houf W., Grief R., 1985, Numerical modeling of a solid particle solar central receiver, Sandia National Laboratories, Sandia report, SAND85-8249.

Chen H., Chen Y., and Hsieh H. T., 2007, Computational Fluid Dynamics Modeling of Gas-Particle Flow Within a Solid-Particle Solar Receiver, Journal of Solar Energy Engineering, Volume 129, Issue 2, pp. 160-170.

Hruby J. M., 1986, A technical feasibility study of a solid particle solar central receiver for high temperature applications, Sandia National Laboratories, Sandia report, SAND868211.

Hruby J. M., and Burolla V. P., 1984, Solid particle receiver Experiments: Velocity Measurements, Sandia National Laboratories, SAND84-8238.

Patankar S. V., 1980, Numerical heat transfer and fluid flow, Hemisphere, New York. Fluent Inc., 2005, Fluent users guide, version 6.3.26, Lebanon, USA. 


\section{Table captions:}

Table 1. Operating conditions of gas flow and physical properties of the solid particle

Table 2. Total energy, absorbed heat and heat loss for the baseline case (integrated energy source is $2070 \mathrm{~kW}$ and the particle size is $650 \mu \mathrm{m}$, no air-jet flow)

Table 3. Cavity efficiencies and average exit particle temperatures with different air-jet velocities and different air-jet temperatures

\section{Figure captions:}

Figure 1. Conceptual design of the SPR with dimensions (unit: m, the Lines 1 and 2, Points A and Bare the typical locations for the result processing and analysis).

Figure 2. Velocity magnitudes along Line 1.

Figure 3. Velocity magnitudes along Line 2.

Figure 4. Velocity relative errors compares to the finest mesh at Point A.

Figure 5. Velocity relative errors compares to the finest mesh at Point B.

Figure 6. Air flow pattern at the plane $\mathrm{x}=1 \mathrm{~m}$, without an air-jet flow $\left(V_{a j}=0\right)$.

Figure 7. Temperature contours $(\mathrm{K})$ at the plane $\mathrm{x}=1 \mathrm{~m}$, without an air-jet flow $\left(V_{a j}=0\right)$.

Figure 8. Air flow pattern at the plane $\mathrm{x}=1 \mathrm{~m}$, with an air-jet flow $V_{a j}=8 \mathrm{~m} / \mathrm{s}$.

Figure 9. Temperature contours $(\mathrm{K})$ at the plane $\mathrm{x}=1 \mathrm{~m}$, with an air-jet flow $V_{a j}=8 \mathrm{~m} / \mathrm{s}$.

Figure 10. Cavity efficiencies of the SPR and average exit particle temperatures vs. air-jet velocities.

Figure 11. Radiation loss and convection loss percentages vs. air-jet velocities. 
Figure 12 Air flow stream lines released from the air-jet (colored by temperature, $V_{a j}=8$ $\mathrm{m} / \mathrm{s}$, and $\left.T_{a j}=700 \mathrm{~K}\right)$.

Figure 13 Air flow stream lines released from the air-jet (colored by temperature, $V_{a j}=8$ $\mathrm{m} / \mathrm{s}$, and $\left.T_{a j}=300 \mathrm{~K}\right)$.

Figure 14. Cavity efficiency and average exit particle temperature vs. particle diameters ( $V_{a j}=8 \mathrm{~m} / \mathrm{s}$, and $T_{a j}=300 \mathrm{~K}$, mass flow rate is $5 \mathrm{~kg} / \mathrm{s}$, and solar flux is 920 suns).

Figure 15. Cavity efficiency and average exit particle temperature vs. particle mass flow rates ( $T_{a j}=300 \mathrm{~K}$, diameter of particles is 650 micron, and solar flux is 920 suns). 
Figure 1

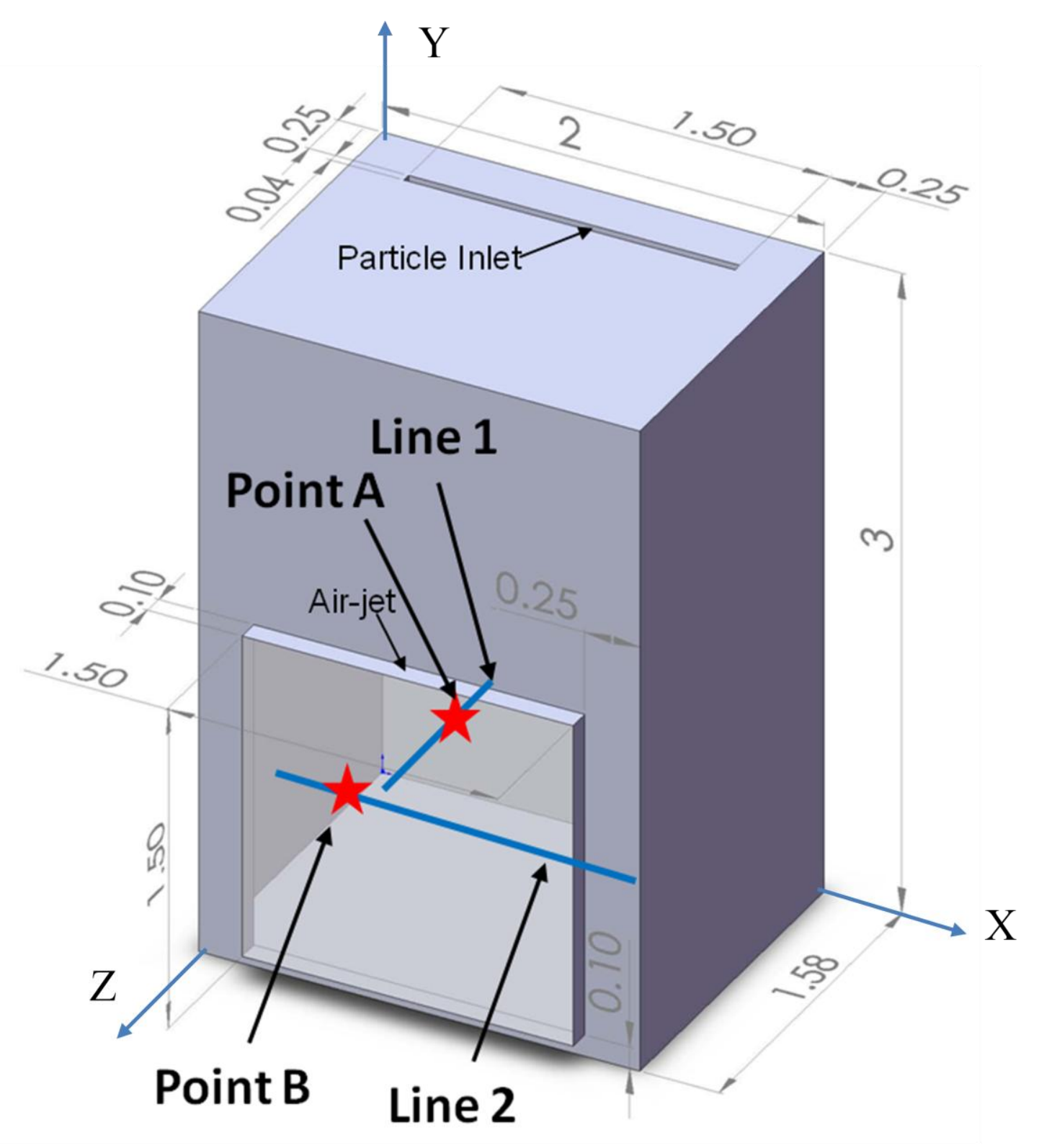


Figure 2

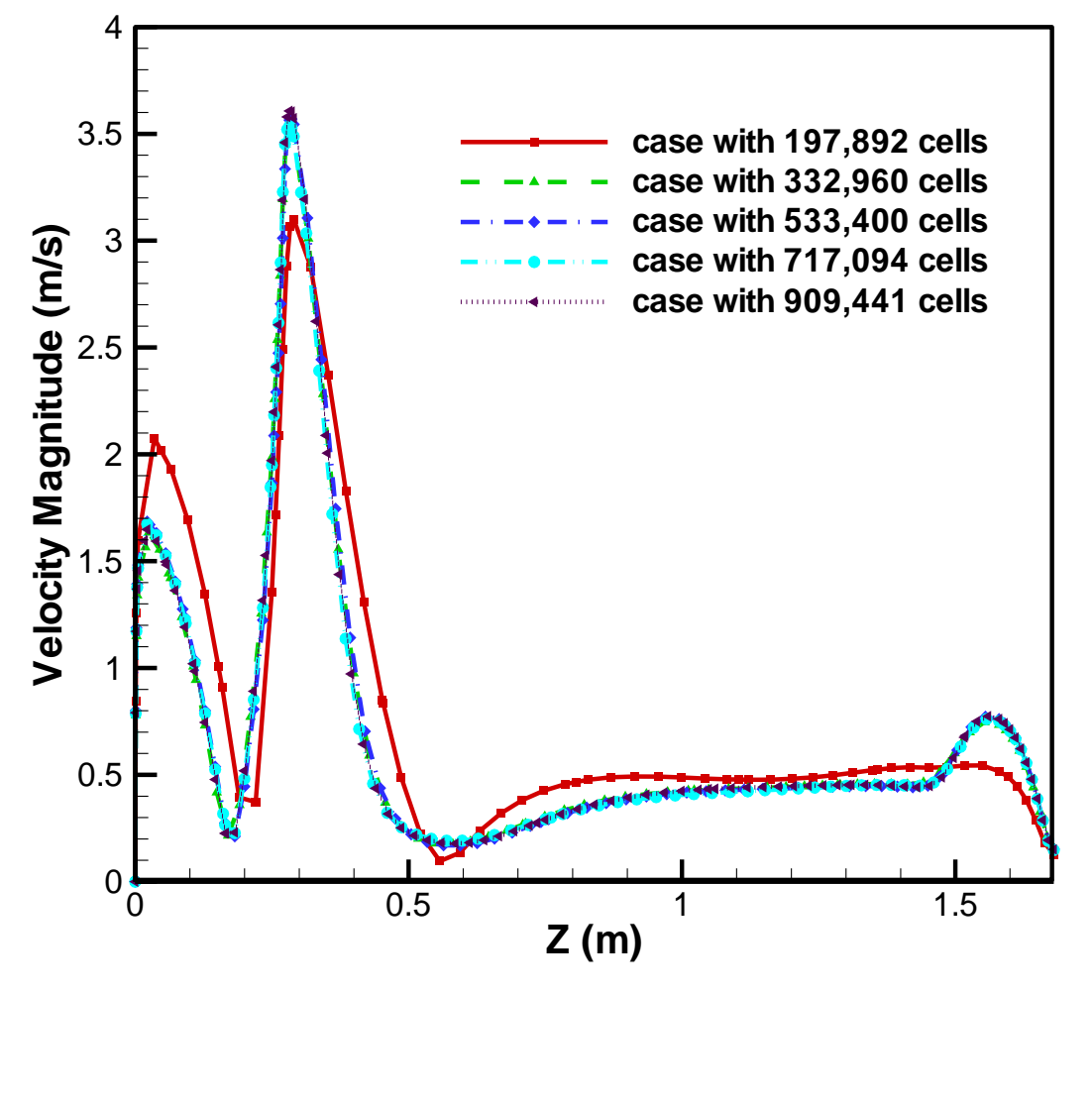

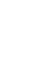
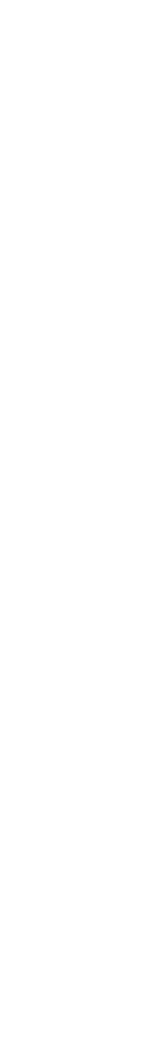


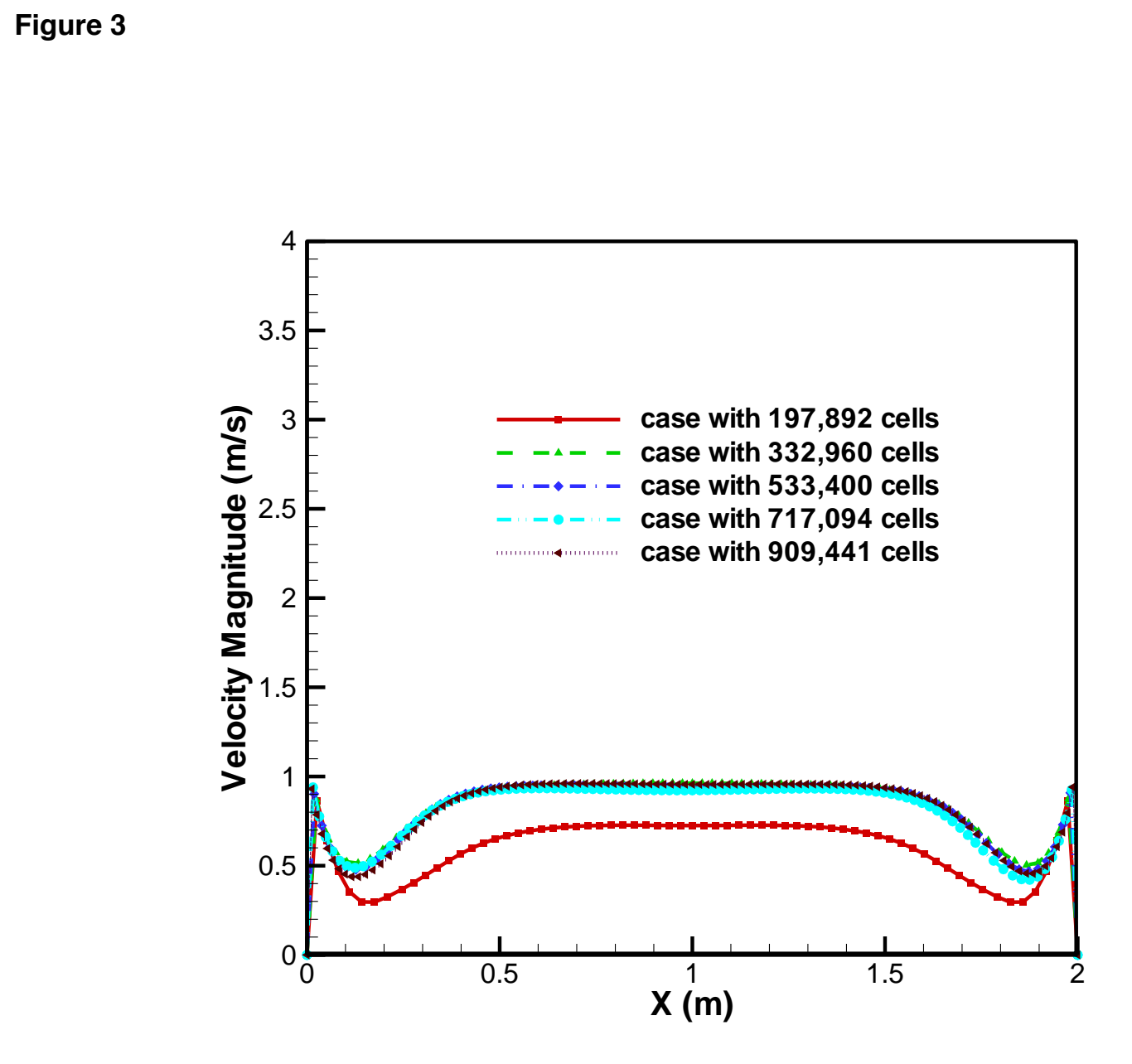

Figure 3
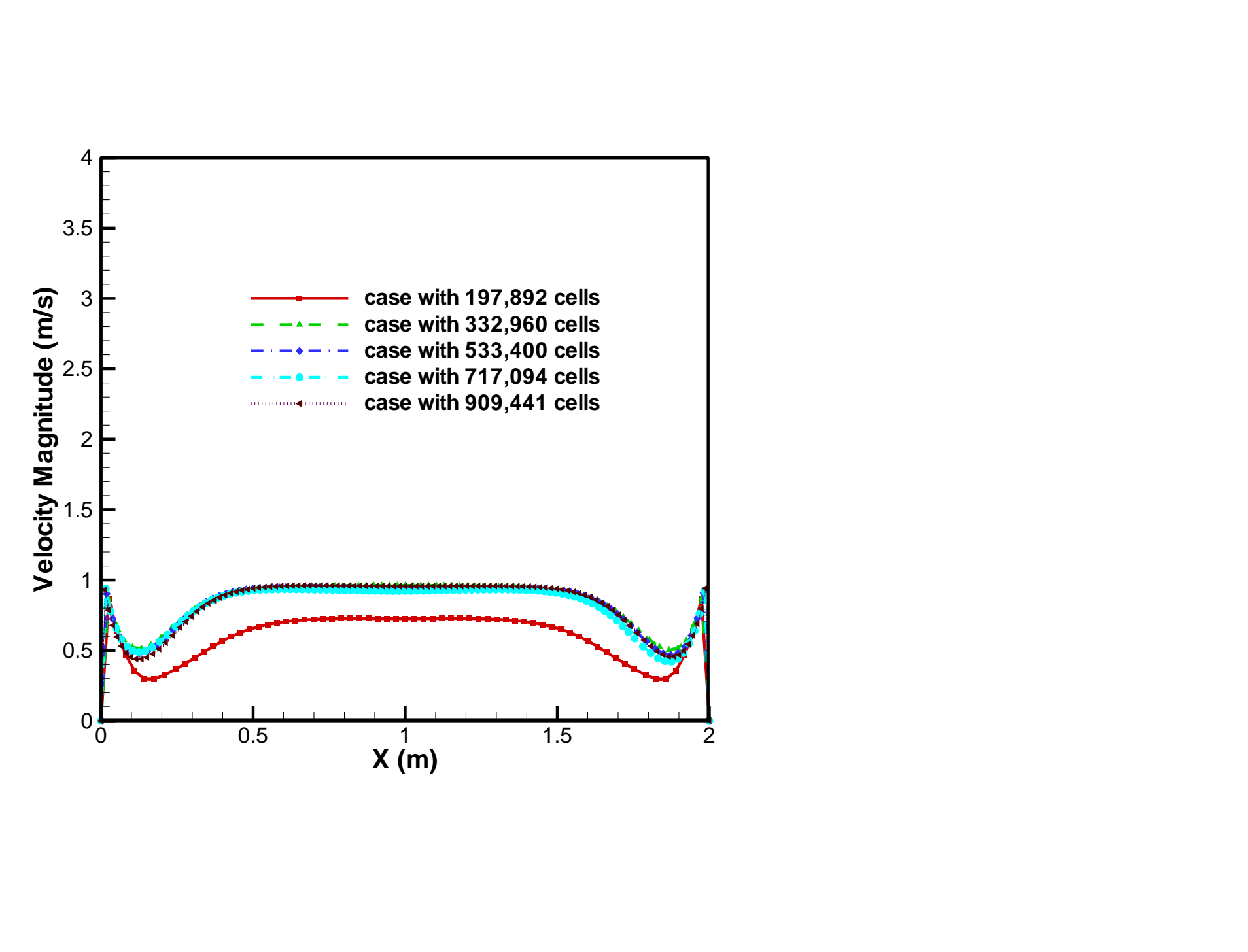

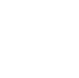

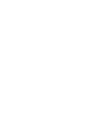

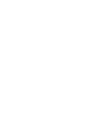

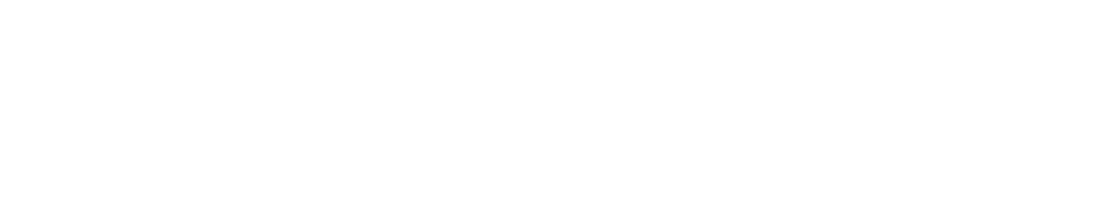




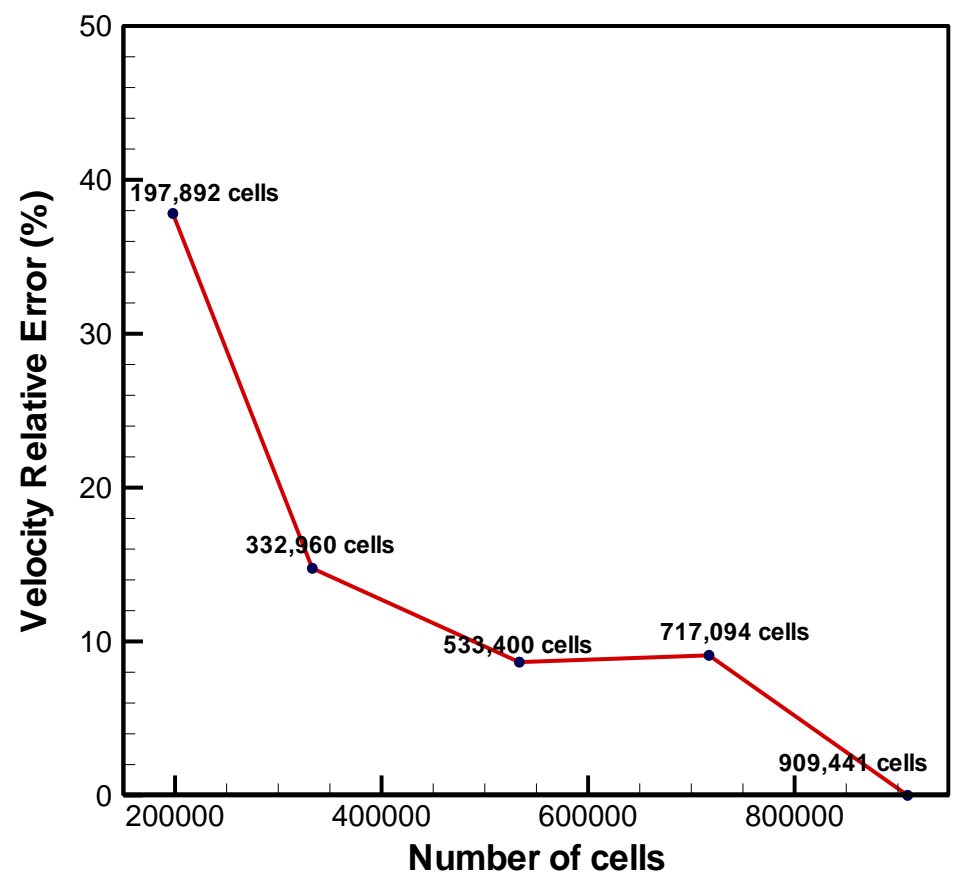

Number of cells 


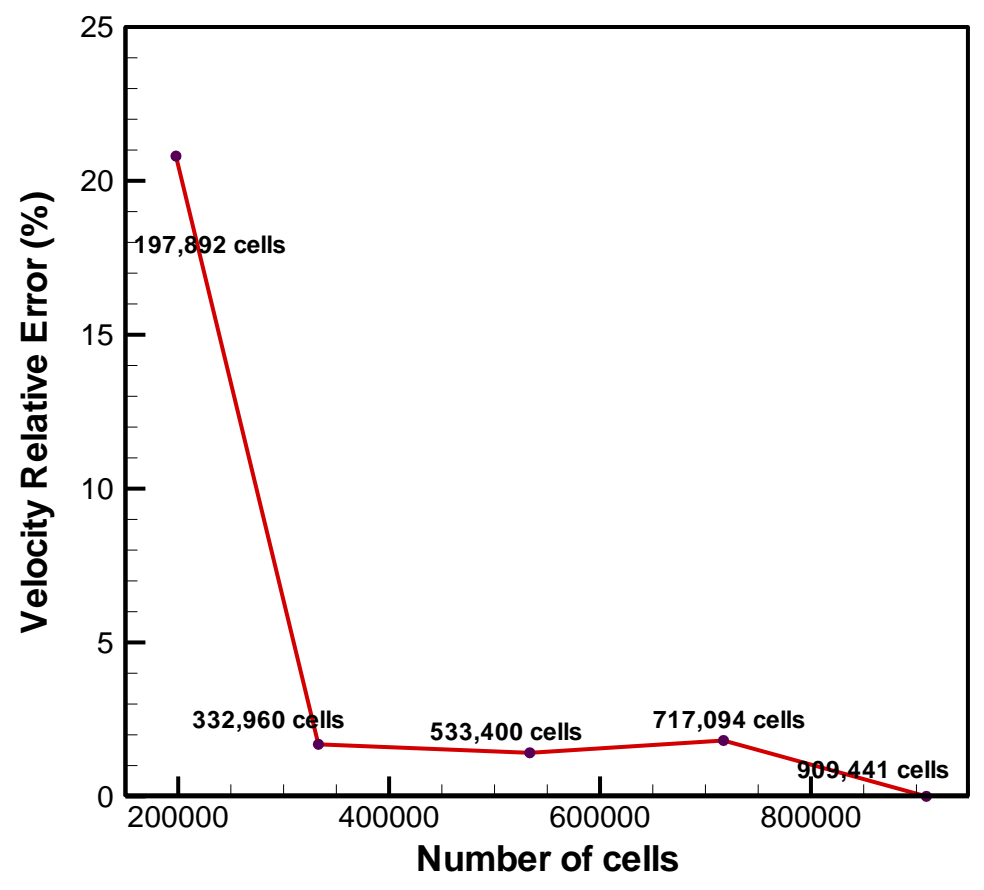

Figure 5

Number of cells 


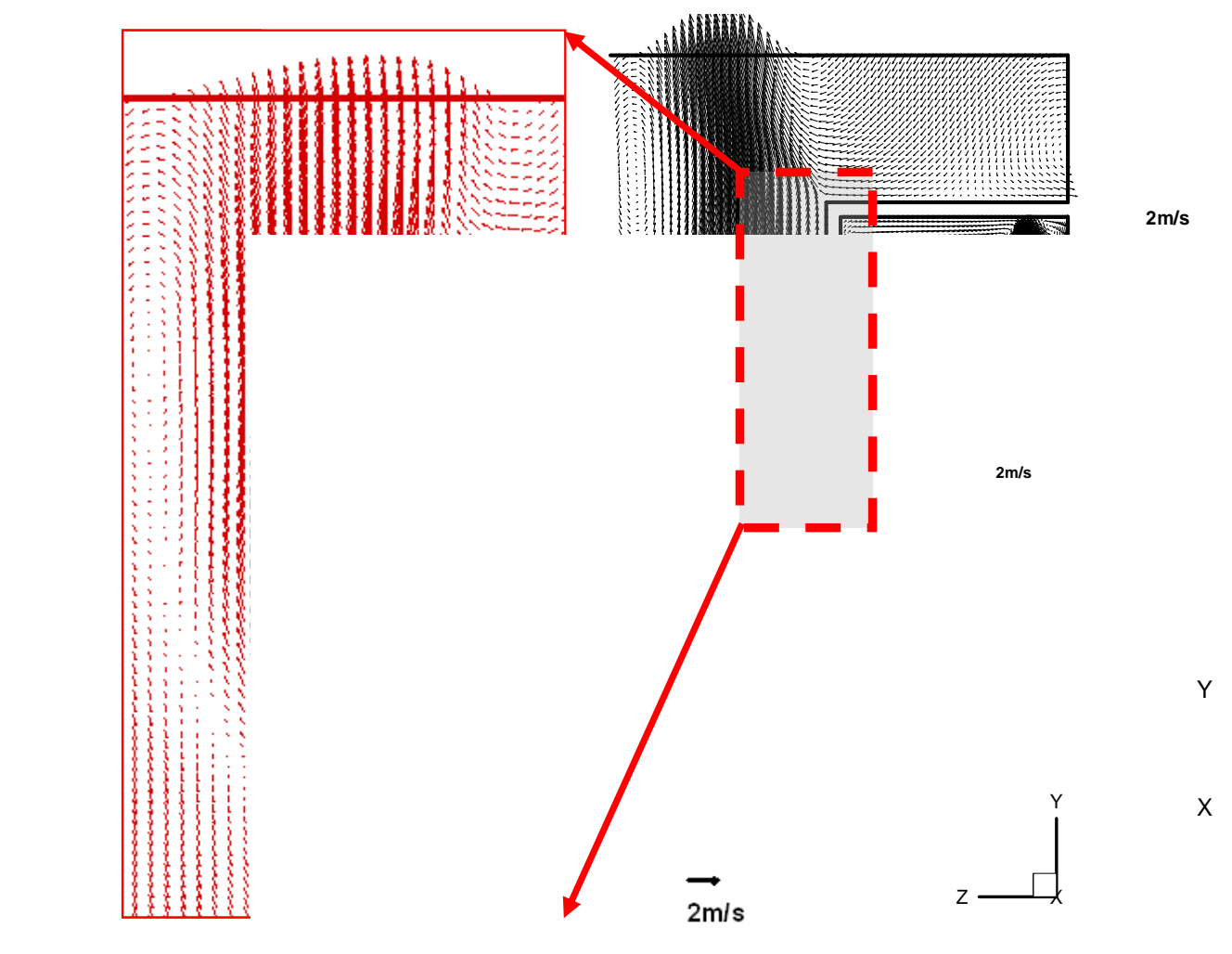

Figure 6

$x$

\section{Figure 6}

$\times$
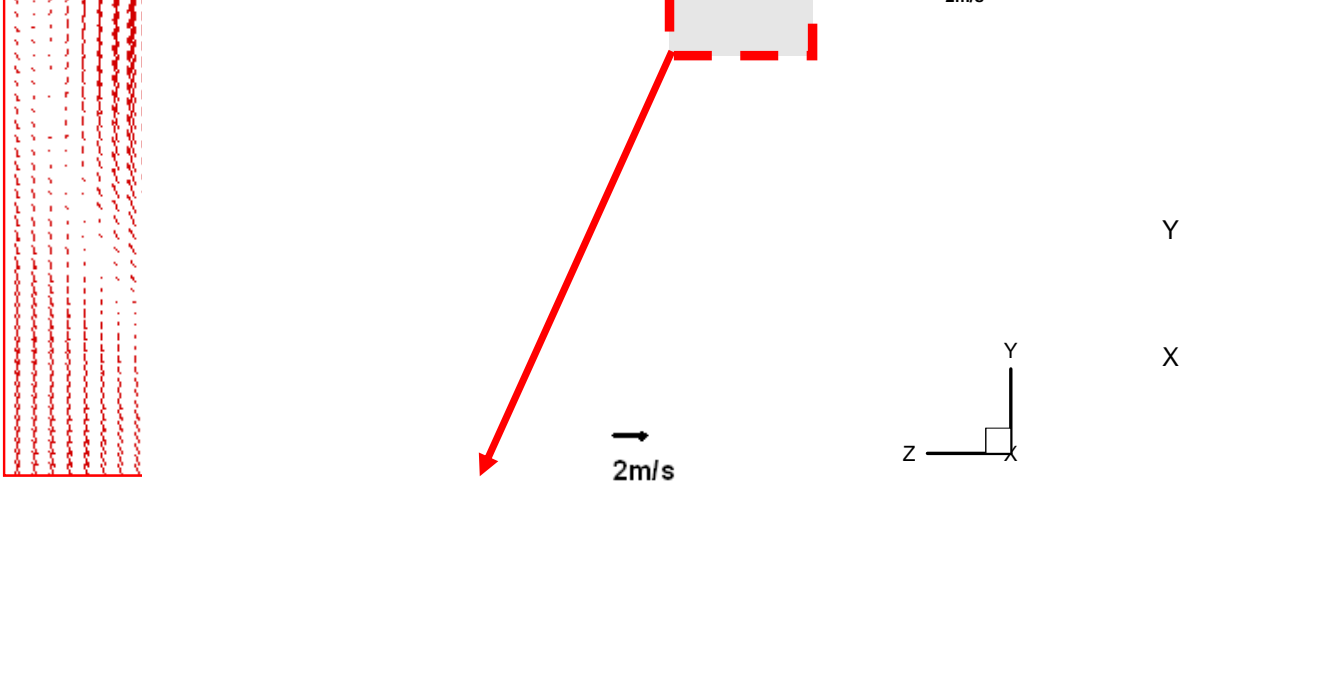
Figure 7

\begin{tabular}{c|c} 
temperature & temperature (K) \\
2100 & 2100 \\
2000 & 2000 \\
1900 & 1900 \\
1800 & 1800 \\
1700 & 1700 \\
1600 & 1600 \\
1500 & 1500 \\
1400 & 1400 \\
1300 & 1300 \\
1200 & 1200 \\
1100 & 1100 \\
1000 & 1000 \\
900 & 900 \\
800 & 800 \\
700 & 700 \\
600 & 600 \\
500 & 500 \\
400 & 400 \\
&
\end{tabular}

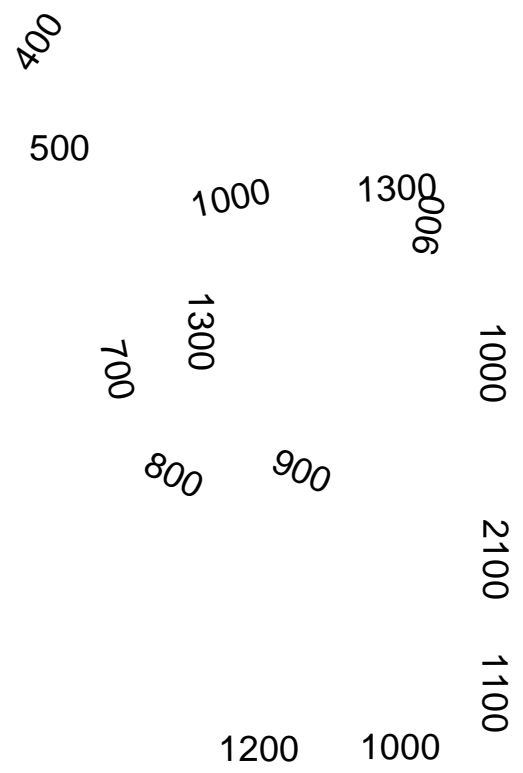




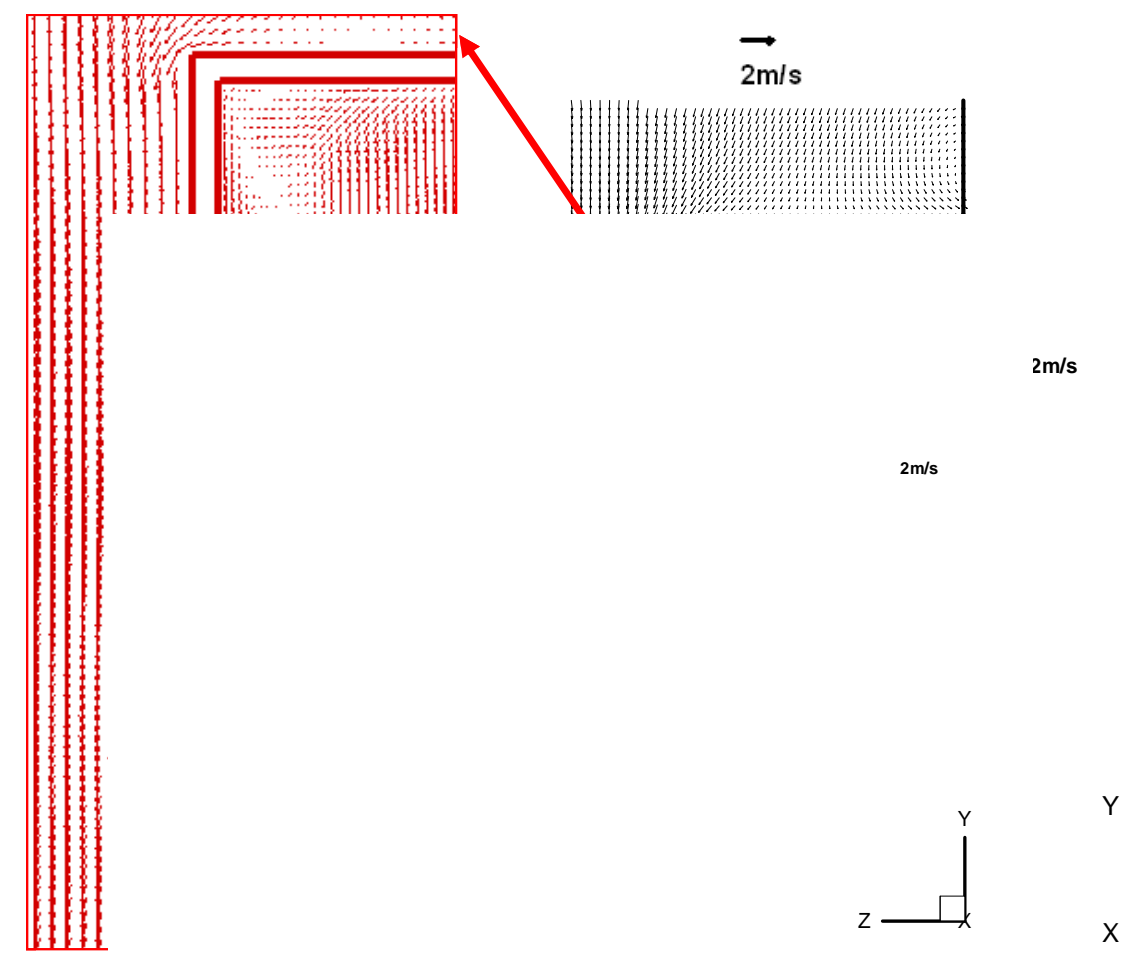


Figure 9

\begin{tabular}{c|l} 
temperature (K) & temperature (K) \\
2100 & 2100 \\
2000 & 2000 \\
1900 & 1900 \\
1800 & 1800 \\
1700 & 1700 \\
1600 & 1600 \\
1500 & 1500 \\
1400 & 1400 \\
1300 & 1300 \\
1200 & 1200 \\
1100 & 1100 \\
1000 & 1000 \\
900 & 900 \\
800 & 800 \\
700 & 700 \\
600 & 600 \\
500 & 500 \\
400 & 400 \\
&
\end{tabular}

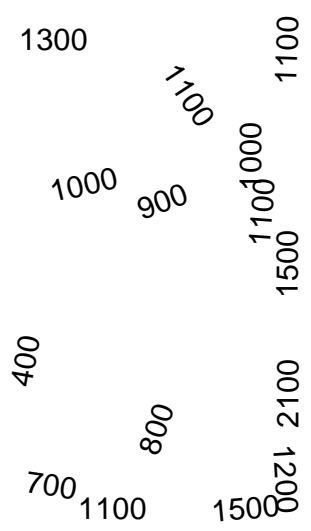


Figure 10

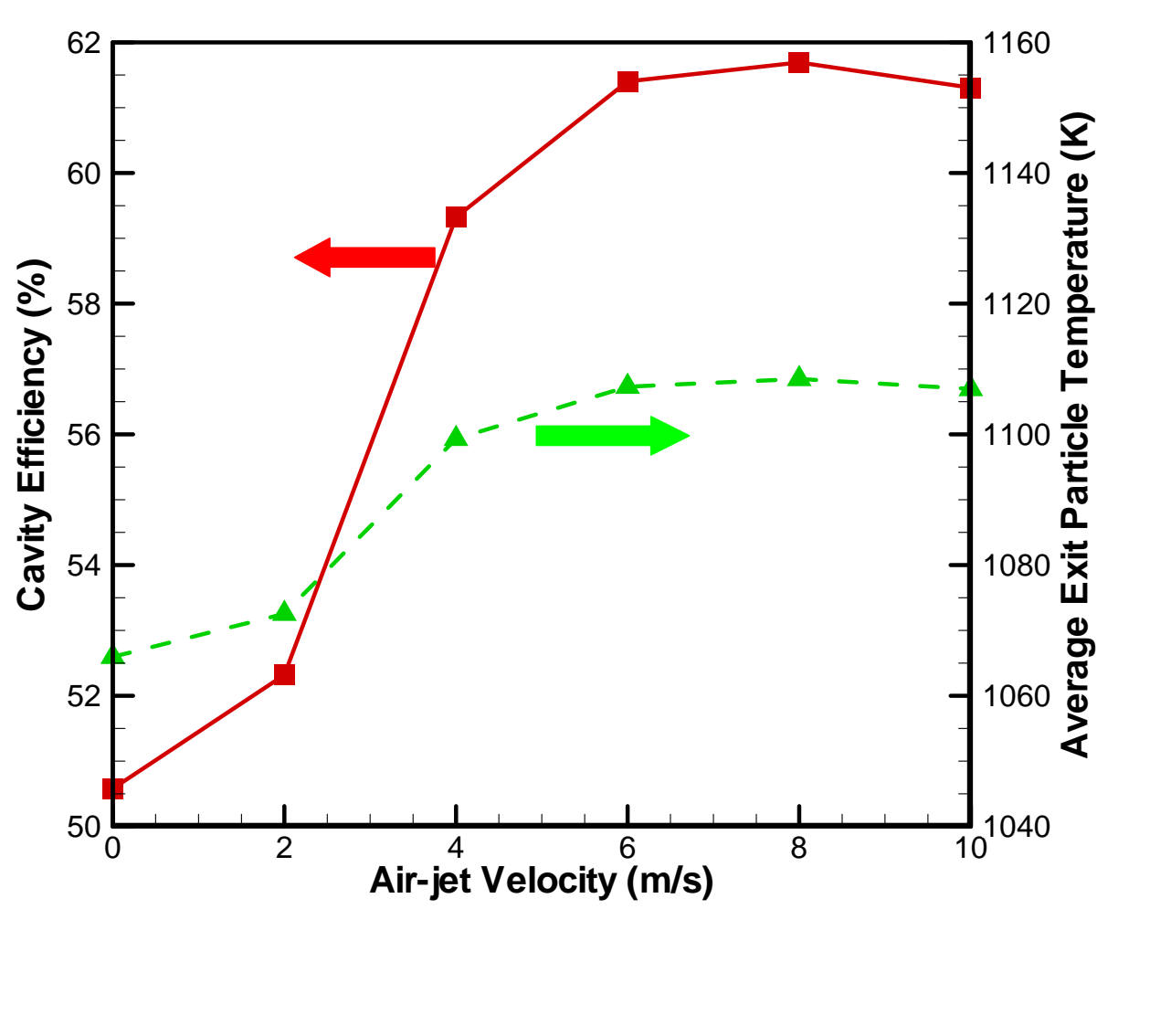

.

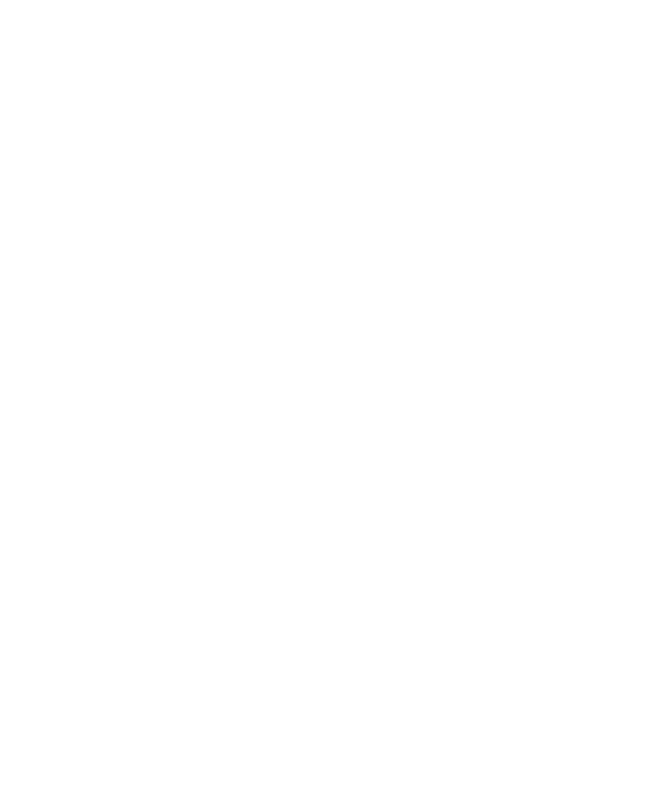

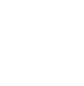

(1)
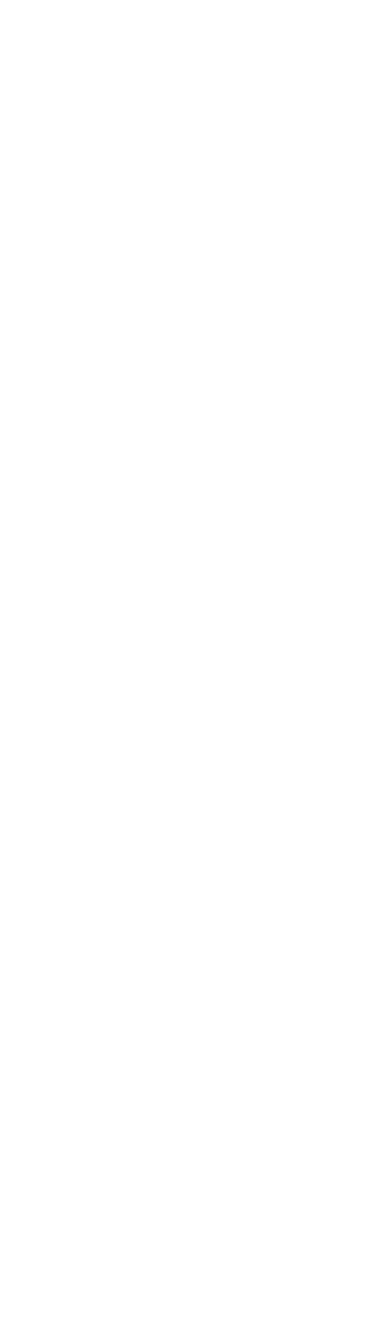


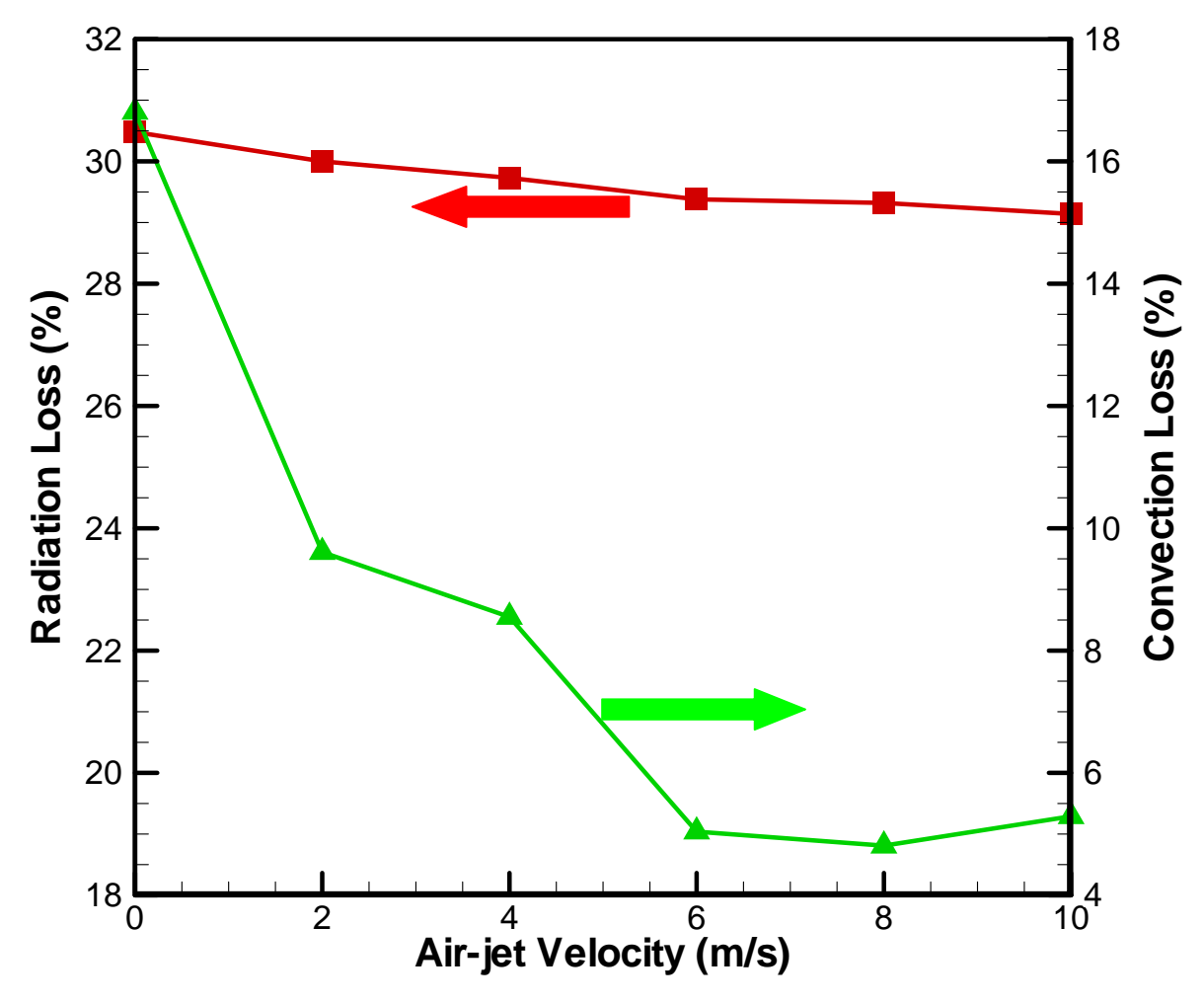

Figure 11 


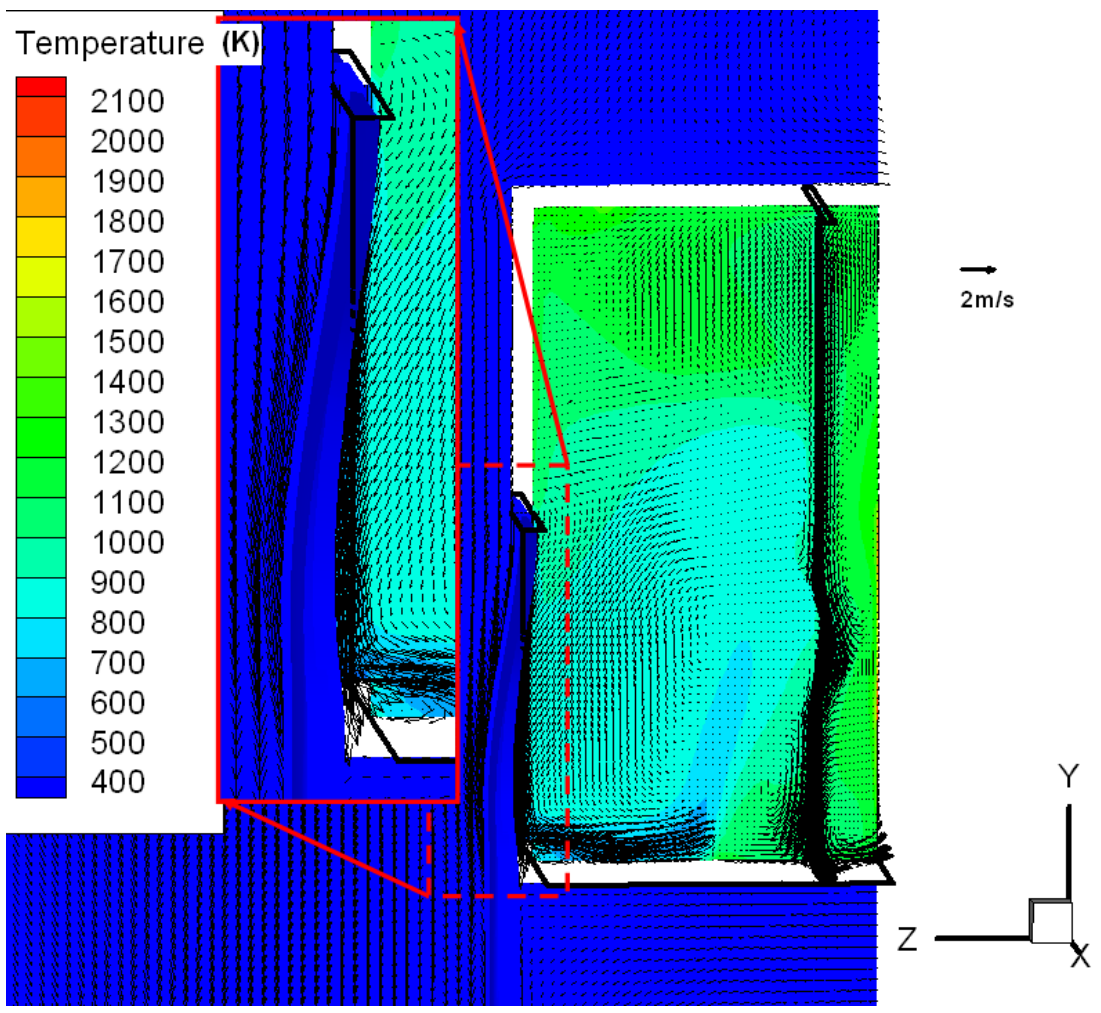

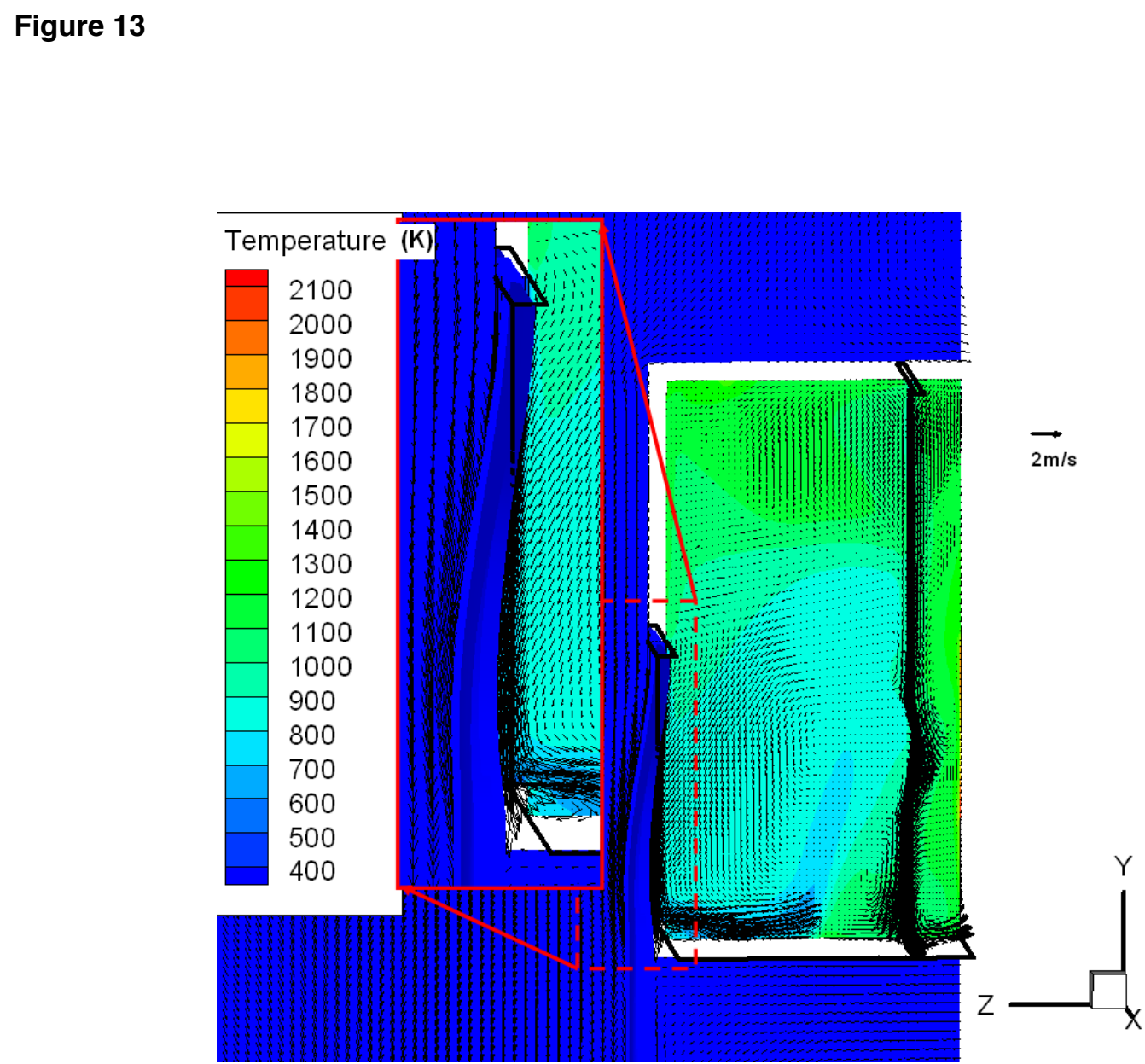




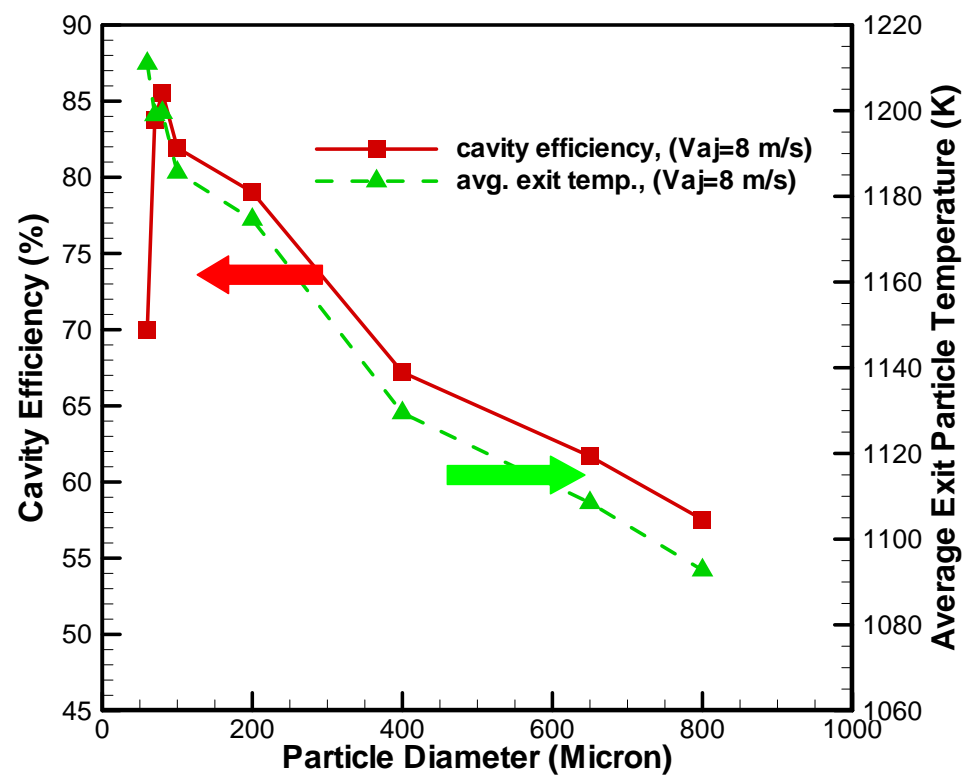

Figure 14

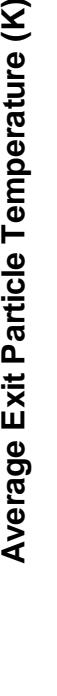




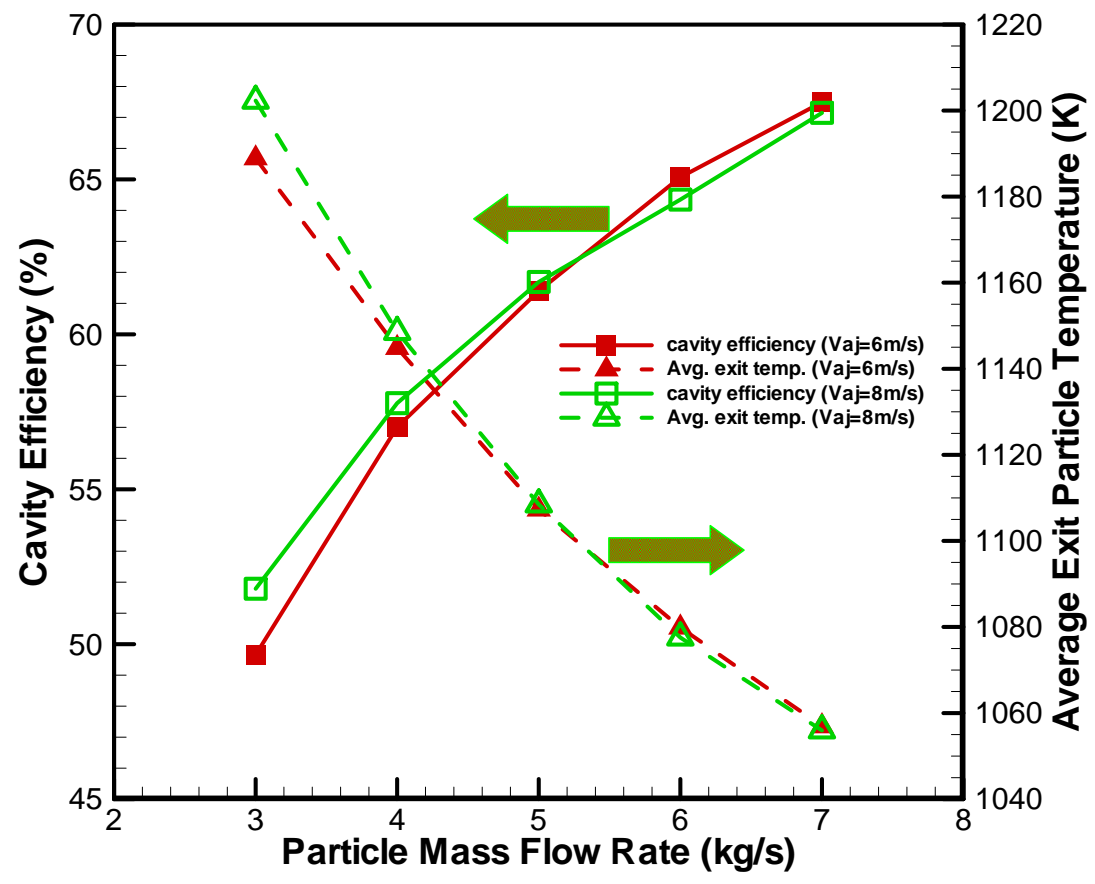


Table 1. Operating conditions of gas flow and physical properties of the solid particle

\begin{tabular}{|c|c|}
\hline Gas Flows & Solid Particle \\
\hline Flow Medium: Air & Particle Density:3,200 kg/m ${ }^{3}$ \\
\hline Incompressible Ideal Gas $)$ & Heat Capacity: $1,085 \mathrm{~J} / \mathrm{kg}-\mathrm{K}$ \\
\hline Air Flow Velocity: 0-10 m/s & Thermal Conductivity:6.67 W/m-K \\
\hline Inlet Air-jet Temperature : & \\
$300-700 \mathrm{~K}$ & Particle Diameter:60- $800 \mathrm{microns}$ \\
\hline Operating Pressure: & \\
\hline 101,000 Pa & \\
\hline $\begin{array}{c}\text { Density: } \rho=\rho(\mathrm{T}) \\
\rho=1.204 \mathrm{~kg} / \mathrm{m}^{3}, \text { at } 20{ }^{\circ} \mathrm{C}\end{array}$ & \\
\hline $\begin{array}{c}\text { Heat Capacity: } 1.012 \mathrm{~J} / \mathrm{kg}-\mathrm{K}(\text { At } \\
\text { Typical Room Conditions })\end{array}$ & \\
\hline
\end{tabular}


Table 2. Total energy, absorbed heat and heat loss for the baseline case (integrated energy source is $2070 \mathrm{~kW}$ and the particle size is $650 \mu \mathrm{m}$, no air-jet flow)

\begin{tabular}{|l|r|r|}
\hline & Amount $(\mathrm{kW})$ & Percentage \\
\hline Total incident solar energy & 2070 & \\
\hline Heat absorbed by particles & 803.16 & $38.80 \%$ \\
\hline Convection loss & 635.49 & $30.70 \%$ \\
\hline Radiation loss & 631.35 & $30.50 \%$ \\
\hline
\end{tabular}


Table 2. Cavity efficiencies and average exit particle temperatures with different air-jet velocities and different airjet temperatures

\begin{tabular}{|c|c|c|c|c|c|c|}
\hline \multirow{2}{*}{$\begin{array}{c}\text { Velocity of Air-jet } \\
(\mathrm{m} / \mathrm{s})\end{array}$} & \multicolumn{2}{|c|}{6} & \multicolumn{2}{|c|}{8} & \multicolumn{2}{c|}{10} \\
\cline { 2 - 7 } $\begin{array}{l}\text { Temperature of } \\
\text { Air-jet (K) }\end{array}$ & $\eta$ & $T_{P-\text { exit }}(\mathrm{K})$ & $\eta$ & $T_{P-\text { exit }}(\mathrm{K})$ & $\eta$ & $T_{P-\text { exit }}(\mathrm{K})$ \\
\hline 300 & 0.61 & 1,107 & 0.62 & 1,108 & 0.61 & 1,106 \\
\hline 500 & 0.61 & 1,105 & 0.60 & 1,104 & 0.62 & 1,111 \\
\hline 700 & 0.60 & 1,100 & 0.61 & 1,105 & 0.61 & 1,106 \\
\hline
\end{tabular}

